\title{
Out of Sight, Out of Mind: Capturing the Distance (Online) Learner Experience
}

\author{
Rachel Fitzgerald, The University of Northampton \\ Paul Corazzo, Moulton College
}

\begin{abstract}
This work in progress paper presents the findings of a small scale study conducted to gain insight into the 'distance learner' experience at a higher education institution. The study was undertaken in support of a wider project to improve and enhance online learning. Primary research was undertaken by an undergraduate student who conducted virtual focus groups with currently enrolled students using face to face video technology. This report documents the method and limitations of undertaking the research and summarises participants' thoughts. Initial outcomes from the study suggest that students are generally content with learning and teaching online, but experience frustration with aspects of administration and course material signposting. Participants make a number of recommendations for overall improvement and this report concludes with plans for going forward and embedding their ideas into the wider project and developing opportunities for further student input to their learning.
\end{abstract}

Keywords: Online learning; distance learning; student experience; online focus groups; student voice.

\section{Introduction}

This work in progress report is the outcome of a small scale study that captured the views of students engaged in various online learning courses within a Business School at a UK university. This study was undertaken by a student researcher as part of a wider development by the School to develop and enhance the online student experience. The main purpose of the study was to gain some feedback from online and distance learners. While online learning is a growth area, little is known about 'students' expectations and experiences', (Paechter et al., 2010, p.222). Those engaged in the project found that feedback from this student group is limited as distance students often do not return module evaluations. Anecdotal feedback suggests that academics assume distance learners are happy to just get on with it; that online students are just more independent (Diaz \& Cartnal, 1999). There appears to be an assumption by academics that online learners require very little support, but the research suggests that this group of students are likely to need much more specific support (Chen \& Yang, 2010; Lee et al., 2011).

Universities face a time of 'significant transformation of university business models' (Bokor, 2012 , p.15). The introduction of fees and a downturn in the economy puts additional pressure on both learners and institution, requiring more innovative approaches to study. Online study 'offers a flexible study option for people who can't commit to fulltime study, or don't have access to a nearby university' (Page, 2013, online). The Business School wishes to increase their range of online learning programmes to open opportunities and increase market share. To ensure success, 
academics involved in teaching and learning online will need to become more aware of their role in learner motivation (Inman et al., 1999; Hartnett et al., 2011). Chen and Yang (2010, p.750) suggest that online instructors can support online students more effectively if they create an 'open, interactive, and learner-centred' atmosphere for students, and Lee et al. (2011) found that learner satisfaction and course optimization comes from good student support. This study will offer some insight into the student experience of such support and learner centeredness. Outcomes will be used to identify areas for improvement in the overall quality of the online student experience, and possibly contribute to future staff development.

\section{The Research}

\section{Methodology, Sampling Method and Data Collection}

A qualitative approach was used with a convenience sample of online students. Participation was voluntary and any student with experience of distance learning at the Business School was invited to participate. An email was sent to all distance learners in the school advising them of the purpose and method of the study, the themes for discussion and information about the student researcher. Students were asked to sign up to one of the online focus groups via Google Forms. Participants were made aware that the sessions would be recorded and that the data would only be used for the purpose of this study, after which recordings would be deleted.

Primary data collection was undertaken by an undergraduate student researcher taking part in a 'student as researcher' initiative. As this study took place over a relatively short period (four months), it was considered impractical to interview a large number of students individually. Asking the students to participate in a focus group offered an opportunity to gather a collective perspective from a diverse group (Halcomb et al., 2007). In addition, an online focus group offers students the opportunity to interact virtually with peers. Student interaction develops a real sense of being part of a learning community (Lee et al., 2011). It was expected that a sharing forum would encourage students to contribute developmental ideas in addition to feedback from their own perspective.

Conducting focus groups with distance learners online requires consideration about time zones and technologies. After consultation with a learning technologist, WizIQ was selected as the technology to enable online focus groups. WizIQ is an online 'virtual' classroom that supports multiple contributors and allows participants to see each other and the researcher. This technology also allows sessions to be set up in advance and recorded.

Data collection took place between February and April 2013. The researcher created seven virtual focus group sessions on WizIQ, set to run at various times to encourage time difference participation.

The aim of the research was to include around six students per focus group. Where students could not participate in a focus group due to technical difficulties, they were offered an opportunity to have a one to one telephone interview. Despite a number of emails sent to eligible students, actual take up was poor. In total, 22 students took part in the study. Of these, only 15 participated in focus group sessions and the largest focus group consisted of four students. 
Participants came from a range of courses, all of which were postgraduate which was a reflection of the online courses available.

Focus groups (and interviews) for qualitative analysis normally employ some form of structure to assist data collection (Halcomb et al., 2007) so the researcher planned some specific themes for discussion. These themes were taken from the wider review and were based on areas normally evaluated in the module feedback amongst others. The themes focused on:

- Expectations and experiences

- Programme and university administration

- Learning materials

- Studying at a distance

- Improving the experience

- What went well?

- Thoughts about being a university student

While students were made aware of the themes, they were offered the opportunity to speak freely about their experiences and thoughts. Participants within focus groups all had an opportunity to contribute and the researcher acted as observer with minimal contribution to the discussion. Discussions were recorded for transcription and summarisation of the conversations during the sessions.

\section{Analysis}

A general summary from the various discussions can be drawn here. It emerged from the discussions that participating students are highly motivated and have clear goals in mind for completing their programmes of study. Generally, participants found that administration issues cause the most difficulties in the overall student experience. Initial enrolment onto programmes appeared to be smooth, but there was a lot of criticism from students regarding re-enrolment onto subsequent years of study. Students were positive overall about the speedy response to email queries by tutors, and expressed satisfaction with the universities' virtual learning environment and library support. Students expressed a need for access to learning materials on the virtual learning environment prior to the start of the programme of study.

'Materials should be with the student plenty of time in advance. Books should be around from the first day of term and should be for the whole year. From day one'.

Participants were, on the whole, satisfied with the learning resources on offer but there was concern expressed about their ability to understand and develop good academic skills. Students appreciated the availability of referencing guides and plagiarism guidelines. One student suggested that their learning experience was particularly enhanced by participation in an online WizIQ class, where they had an opportunity to have direct contact with the module tutor and could ask for guidance regarding assessment requirements and the supporting study skills. There was general agreement about the lack of clarity on VLE sites, and students had consistently 
experienced difficulty finding information, suggesting that signposting learning materials and requirement guidance needed to be less ambiguous.

'Basically I just printed everything off and read through, placed it into the order I thought was best and have continued from there'.

There were mixed feelings about being a distance student. While the participating students appreciated the ability to study at their own convenience and pace, they noted that there were limited opportunities for peer interaction. Where participants experienced peer interaction, it proved favourable. One student commented that a virtual network of support made a vital difference to them personally and helped them to stay on their course.

An area of concern was the number of students that expressed the need for a clearer idea of who their tutor is and in one instance, who was the head of the course.

\section{'Difficult to know who to contact. Is there a head of course? Not sure who to contact'.}

Overall, students were happy to make suggestions to improve the online experience, suggesting the need for a dedicated distance learning (DL) point of contact, particularly to support administration issues, as the students did not want to have to keep emailing tutors. Although focus group participants had very different career and cultural backgrounds, there was a consistent request from all participants for more on-campus help and assistance and students would like more use of technologies, such as WizIQ, when the need for support is at its highest such as assignment submission time. Discussion boards were suggested as a good option for enabling discussion and sharing information.

Under the theme of being a university student, it was interesting to find that some students consider the university to be a course provider. This group did not identify themselves as students of that university and felt no sense of community. Other students, however, actively seek recognition that they are the online equivalent to their on-campus peers. Further research into online learner requirements and motivations will need to be undertaken, to ensure needs of both groups are met.

\section{Limitations of the Study}

The 'success of a focus group may depend upon the skill of its facilitator' (Halcomb et al., 2007, p.1007), and while there was risk in undertaking focus group qualitative research without experience, this was a good opportunity to explore the effectiveness of a virtual focus group. Future research would try to overcome the main limitations to this study which included a small number of participants and technological issues. Technological issues are often an issue in online focus groups (Evidence Base, 2006) and in this instance many students found it difficult to login to the WizIQ platform at the allotted time. As the sessions were being held at odd hours to support time difference, this meant that there was no access to IT support. In addition, focus groups samples may not represent the view of the entire population (Halcomb et al., 2007) and in this instance observations are from a small pool from a single school, and conversations were 
merged from all focus groups into one making it difficult to isolate data from students on particular courses to raise issues. Further research would need to be undertaken to identify if the issues raised were common to specific learners.

\section{Discussion and Conclusions}

The 'student voice' can bring valuable a perspective to learning and teaching practice and can improve quality and engagement (Alkema et al., 2013). Although this study was small, the students involved raised issues that need to be addressed. The observations that emerged from this small study will support development processes for the wider project and will be used in future to evaluative exercises. An example already in practice is where online developments have taken on recommendations about clarity and communications. These courses now offer clear contact information for both academic, administrative and library staff. Other developments include enabling online learners to have access to programme and school information, prior to enrolment. This can be useful as a marketing tool for potential students, and a communication tool with presently enrolled students.

Curriculum development is underway with academic staff to embed clear order and purpose to their online learning materials. Academic staff will be expected to embed appropriate study skill support and engage students through clear signposting. Academics are being given encouragement to engage in discussion boards themselves and start activities with students such as icebreaker introductory discussions at the beginning of each module and to offer support discussions around assessment time. It is hoped that increased use of communication tools such as discussion boards will encourage students to form their own communities of practice. Academics will be offered opportunities to continue to learn new skills in technology-enhanced learning to support more synchronous and asynchronous discussions, including virtual face to face.

While this is a good start, continuous staff development will need to be developed in a strategic manner. Evidence has shown that ongoing and sustained staff development can lead to major improvements in eLearning quality (Samarawickrema \& Stacey, 2007) and we must be willing to enable academics to use supporting technologies to ensure they can engage with students and enable students to engage with each other.

One final thought - this study showed that there is a need for further research on how to enable online distance programmes to enrich students beyond the learning relationship. We need to ensure our learners that are 'out of sight' get a comparable university experience to on-campus learners, and that they feel they are members of our wider university community. It remains to be seen if developing a more transparent, interactive, peer supportive environment will bring about that sense of a virtual community, but as long as we keep students engaged in discussions like these, we are more likely to find out.

\section{References}


Alkema, A., McDonald, H. and Ryan, R. (2013) Student Voice in Tertiary Education Settings: Quality Systems in Practice. New Zealand: Heathrose Research. Available online: http://akoaotearoa.ac.nz/projects/student-voice-effective-representation-and-quality (accessed 19/11/13).

Bokor, J. (2012) University of the Future: A thousand year old industry on the cusp of profound change. Australia: Ernst \& Young Higher Education Report. Available online:

http://www.ey.com/Publication/vwLUAssets/University_of_the_future/\$FILE/University_of_the future_2012.pdf (accessed 19/11/13).

Chen, K. and Jang, S. (2010) 'Motivation in online learning: Testing a model of selfdetermination theory'. Computers in Human Behavior, 26 (4): 741-752.

http://dx.doi.org/10.1016/j.chb.2010.01.011

Diaz, D. and Cartnel, R. (1999) 'Students' Learning Styles in Two Classes: Online Distance Learning and Equivalent On-Campus’. College Teaching, 47 (4): 130-135. http://dx.doi.org/10.1080/87567559909595802

Evidence Base (2011) Focus Groups. eValued: An evaluation toolkit for e-library developments. Available online: http://www.evalued.bcu.ac.uk/tutorial/4b.htm (accessed 19/11/13).

Halcomb, E. J., Gholizadeh, L., DiGiacomo, M., Phillips, J. and Davidson, P. M. (2007) 'Literature review: considerations in undertaking focus group research with culturally and linguistically diverse groups'. Journal of Clinical Nursing, 16 (6): 1000-1011. http://dx.doi.org/10.1111/j.1365-2702.2006.01760.x

Hartnett, M., St. George, A. and Dron, J. (2011) 'Examining motivation in online distance learning environments: Complex, multifaceted, and situation-dependent'. The International Review of Research in Open and Distance Learning, 12 (6): 20-37.

Inman, E., Kerwin, M. And Mayes, L. (1999) 'Instructor and student attitudes toward distance learning'. Community College Journal of Research and Practice, 23 (6): 581-591. http://dx.doi.org/10.1080/106689299264594

Lee, S. J., Srinivasan, S., Trail, T., Lewis, D. and Lopez, S. (2011) 'Examining the relationship among student perception of support, course satisfaction, and learning outcomes in online learning'. The Internet and Higher Education; 14 (3): 158-163. http://dx.doi.org/10.1016/j.iheduc.2011.04.001

Paechter, M., Maier, B. and Macher, D. (2010) 'Students' expectations of, and experiences in elearning: Their relation to learning achievements and course satisfaction'. Computers \& Education, 54 (1): 222-229. http://dx.doi.org/10.1016/j.compedu.2009.08.005

Page, L. (2013) 'Lectures in your living room: Meet the online learners who fit study around their lives'. The Guardian Online, $12^{\text {th }}$ November 2013. Available online: 
http://www.theguardian.com/education/2013/nov/12/online-learning-students-benefits (accessed $12 / 11 / 13)$

Samarawickrema, G. and Stacey, E. (2007) 'Adopting web-based learning and teaching: A case study in higher education'. Distance Education, 28 (3): 313-333.

http://dx.doi.org/10.1080/01587910701611344

\section{About the Authors}

Rachel Fitzgerald is the Head of Special Projects (DL Development), Northampton Business School, University of Northampton.

Email: $\underline{\text { Rachel.Fitzgerald@northampton.ac.uk }}$

Paul Corazzo is a student on the FdSc Agriculture at Moulton College. He undertook this study as part of the URB@N scheme at The University of Northampton:

www.northampton.ac.uk/urban 